\title{
Binaural Response Organization Within a Frequency-Band Representation of the Inferior Colliculus: Implications for Sound Localization
}

\author{
Jeffrey J. Wenstrup, Linda S. Ross, and George D. Pollak \\ Department of Zoology, University of Texas at Austin, Austin, Texas 78712
}

The auditory system of the mustache bat (Pteronotus parnellii) contains a disproportionately large representation of a narrow frequency band, corresponding to the dominant, $60 \mathrm{kHz}$ component of its echolocation signal. In the inferior colliculus (IC), the $60 \mathrm{kHz}$ representation comprises an architectonically distinct region called the dorsoposterior division (DPD), which is accessible for detailed physiological study. We examined the topographic distribution of binaural responses within this one frequency-band representation of the inferior colliculus.

We describe two primary results. First, neurons with different binaural response properties are spatially segregated into one of four binaural response-specific regions of the DPD: a large region of monaural (EO) responses; two regions containing neurons excited by sound from both ears (EE); and a region containing neurons excited by one ear and inhibited by the other (EI). Regions dominated by $60 \mathrm{kHz}$ EI responses are also found in the lateral extremity of the IC, probably within the external nucleus. These results demonstrate functionally defined subdivisions in a single frequency-band representation of the IC. Moreover, they suggest that brain stem auditory projections to the DPD and/or intrinsic connections within the DPD are highly organized.

Second, within the EI region of the DPD, there is a systematic shift in the sensitivity of EI multiunit responses to interaural intensity disparities (IIDs). Dorsally, EI neurons are suppressed only by relatively loud ipsilateral sounds, and there is a systematic decrease in the relative ipsilateral intensity required for suppression at more ventral recording sites. This result demonstrates that neurons sensitive to a sound localization cue are systematically organized within a frequency-band representation of the inferior colliculus. It has implications for the manner in which the location of a sound source is encoded within the primary auditory pathway.

Within the primary auditory pathway of mammals, the central nucleus of the inferior colliculus (ICC) receives nearly all information ascending from the brain stem (Aitkin and Phillips, 1984; Goldberg and Moore, 1967). Some nine brain stem nuclei, each containing distinct physiological properties, project to the ICC (Adams, 1979; Beyerl, 1978; Roth et al., 1978; Schweizer, 1981; Zook and Casseday, 1982b). The brain stem nuclei are tonotopically organized (Aitkin et al., 1970; Goldberg and Brown,

\footnotetext{
Received May 21, 1985; revised Sept. 20, 1985; accepted Sept. 25, 1985.

We thank Drs. Z. Fuzessery, J. Winer, and J. Zook for thoughtful comments on the manuscript, C. Resler for technical assistance, and J. Young for artwork This work was supported by P.H.S. Grants NS13276 and NS21 286 to G.D.P. and NS07733 to J.J.W. Preliminary reports have appeared (Ross et al., 1983; Wenstrup et al., 1983, 1985a).

Correspondence should be addressed to Jefrey J. Wenstrup, Department of Physiology-Anatomy, University of California, Berkeley, CA 94720.

Copyright (C) 1986 Society for Neuroscience 0270-6474/86/040962-12\$02.00/0
}

1968; Guinan et al., 1972; Rose et al., 1959; Tsuchitani, 1977), yet their topographically ordered projections converge on a single tonotopic organization in the ICC (FitzPatrick, 1975; Merzenich and Reid, 1974; Semple and Aitkin, 1979; Servière et al., 1984). Collicular neurons that are most sensitive to nearly the same frequency of sound are grouped within characteristic laminae of the ICC (Merzenich and Reid, 1974; Morest, 1964; Oliver and Morest, 1984; Rockel and Jones, 1973; Semple and Aitkin, 1979; Servière et al., 1984). These frequency-band laminae receive convergent input from the corresponding frequency-band representations of brain stem auditory nuclei (BrunsoBechtold et al., 1981; Roth et al., 1978; Zook and Casseday, 1982b). Thus, they contain a full complement of the ascending information required to analyze the features of a sound within a particular frequency band.

How are physiological responses that are related to sound location organized within the frequency-band laminae of the ICC? It is generally accepted that the location of a sound is encoded in part by the responses of binaural neurons sensitive to interaural time or intensity disparities. Binaural interactions first occur in the nuclei of the superior olivary complex. These nuclei, differing in their binaural properties, project to the ICC, where several types of binaural neurons are present (Rose et al., 1966; Roth et al., 1978; Semple and Aitkin, 1979; Stillman, 1972). The tonotopic organization of these projections and their termination within different zones of the ICC suggest that each frequency-band lamina of the ICC contains a segregation of binaural response classes (Brunso-Bechtold et al., 1981; Henkel and Spangler, 1983; Roth et al., 1978; Zook and Casseday, $1982 \mathrm{~b}$ ). This has been demonstrated by the physiological studies of Roth et al. (1978) and Semple and Aitkin (1979). Such results raise the possibility that a topographic organization of sound localization cues may be found within frequency-band laminae of the ICC. However, it has been difficult to examine such topographic featurcs within the thin, sheetlike frequency-band representations ("isofrequency laminae") of most mammals.

The IC of the mustache bat (Pteronotus parnellii) provides a unique opportunity to examine the topographic organization of a collicular frequency-band region. The mustache bat's ICC contains a tonotopic organization in common with other mammals (e.g., Aitkin et al., 1972; Clopton and Winfield, 1973; FitzPatrick, 1975; Merzenich and Reid, 1974; Rose et al., 1963). However, the representation of a narrow frequency band, corresponding to the dominant, $60 \mathrm{kHz}$ component of the bat's echolocation signal, is disproportionately enlarged and fills about one-third of the central nucleus (Pollak and Bodenhamer, 1981; Zook et al., 1985). This architectonically distinct region, called the dorsoposterior division (DPD), provides a massive, accessible, frequency-band representation for detailed physiological study. We examined the distribution of binaural responses in the DPD and found a pronounced segregation of binaural response classes. In one segregated binaural region, EI responses 
were systematically arranged according to their sensitivity to interaural intensity disparities (IIDs). This result suggests that sound localization cues may be represented topographically in the ICC.

\section{Materials and Methods}

Binaural responses were recorded from the IC of awake greater mustache bats (Pteronotus parnellii parnellii). Thirty-two mustache bats, captured in Jamaica, West Indies, were studied. Two types of experiments were performed: (1) the topographic distribution of binaural properties was mapped using multiunit recordings, and (2) binaural response properties were examined in detail in single unit recordings.

\section{Surgical procedures}

The dorsal surface of the IC was exposed in bats anesthetized with methoxyflurane (Metofane, Pitman-Moore, Inc.) and sodium pentobarbital (Nembutal, Abbot Laboratories; dosage $10 \mathrm{mg} / \mathrm{kg}$ ). A midline incision was made in the skin overlying the skull, and the muscles were reflected laterally. A sharpened tungsten ground electrode was cemented into the right cerebral cortex, and a small hole was drilled in the skull over the left IC. A long-lasting local anesthetic, lidocaine (Elkins-Sinns, Inc.), was then applied to the open wounds.

Following these procedures, the bat was placed in a Plexiglas restraining apparatus in the heated experimental chamber. The bat's head was held in a uniform position using a bite bar, and then fixed in place by cementing a pin to the skull and securing the pin to the restraining apparatus. Data collection began once the bat had recovered from the general anesthetic. If necessary, the bat was given a subanesthetic dose of Nembutal $(5 \mathrm{mg} / \mathrm{kg})$ and Acepromazine $(2 \mathrm{mg} / \mathrm{kg})$. This dosage sedated the bat but did not appear to significantly affect auditory thresholds. Anesthetic doses of Nembutal or Metofane appreciably increase thresholds of $60 \mathrm{kHz}$ neurons.

\section{Acoustic stimulation}

Tone bursts (30 msec duration, $1 \mathrm{msec}$ rise-fall times, 3-4/sec) were generated by shaping the output of a function generator (Wavetek model 136) with an electronic switch (Grason-Statdler model 1287B). The output of the switch was connected to both channels of a voltage amplifier, whose outputs were, in turn, connected to attenuators (HewlettPackard model 350D). The attenuator outputs were each fed into a Polaroid (model T2004) condenser speaker, with a 200 VDC polarization. The sine wave frequency was monitored with a frequency counter.

Dichotic stimulation was obtained by fitting each Polaroid speaker with funnels ending in a $5 \mathrm{~mm}$, I.D., tube. Each speaker tube was placed within a pinna and sealed into place with ear mold compound. For this dichotic system, the attenuation of acoustic crosstalk was measured as the difference in threshold of the cochlear microphonic response when stimulated by the ipsilateral versus the contralateral speakers. Crosstalk attenuation exceeded $50 \mathrm{~dB}$ with the sealed system.

Since the closed system could not be calibrated directly, the frequency response was tested in a recently deceased bat by placing a Brüel and Kjaer $3.2 \mathrm{~mm}$ microphone in the position normally occupied by the tympanum. From 59 to $65 \mathrm{kHz}$, the sound pressure level at the tympanum varied by less than $10 \mathrm{~dB}$. Both speakers had similar frequency responses. Some resonance effects were seen, but large amplitude fluctuations were not observed over a range of a few hundred Hertz; it is therefore unlikely that these resonances affected the measurement of the excitatory frequency with the lowest threshold in these very sharply tuned neurons (Pollak and Bodenhamer, 1981). When the speaker tube was removed and resealed into the ear, the frequency response usually changed somewhat. Thus, we could not be sure of the exact intensity or interaural intensity disparity of sound for any subject. However, because we examined responses within a very narrow frequency band, and because the speakers were sealed in place for the duration of each experiment, this uncertainty did not affect our findings.

\section{Recording procedures}

Micropipettes filled with $1 \mathrm{~m} \mathrm{NaCl}$ and $10 \% \mathrm{HRP}$ (Sigma Type VI) were visually placed over the IC, using the surface vasculature as a guide. Because the bat's head was tilted forward during the experiment, dorsoventral penetrations were made at an angle of about $15^{\circ}$ from the vertical. The location of each penetration was plotted onto a drawing of the collicular surface. Electrodes were advanced by a Kopf hydraulic system controlled by a stepping motor outside the experimental chamber. Single units were recorded with unbroken electrodes (resistances 20-40 M $\Omega$ ), while multiunit responses were recorded with electrodes broken to tip diameters of 2-5 $\mu \mathrm{m}$ (resistances 1-5 M $\Omega$ ). Extracellular action potentials were amplified by conventional means and displayed audiovisually. Neural responses were also sent through a window discriminator (Frederick Haer and Co.) to a Declab 11/03 computer, which generated poststimulus time (PST) histograms of responses to 20 stimulus presentations.

The multiunit responses recorded by our electrodes consisted of stimulus-locked clusters of clearly defined spikes. Photographs of oscilloscope tracings suggest that these clusters usually contained two to seven units, varying in spike amplitude and shape. The sensitivity of both the audio monitor and the window discriminator was adjusted to detect spike activity exceeding the baseline noise level. Large, medium, and some smaller amplitude spikes were thereby included in multiunit responses.

In multiunit mapping experiments, responses were sampled at 75 or $100 \mu \mathrm{m}$ increments of depth within dorsoventral penetrations. We first determined the best frequency (BF) of each cluster-the frequency requiring the lowest intensity to elicit stimulus-locked spikes-using contralateral stimulation. The threshold at BF (defined as the lowest intensity required to elicit one or more spikes to each of five stimuli) was determined for both contralateral and ipsilateral stimulation. Binaural response properties were then evaluated as described below. A penetration continued in this manner until an abrupt shift in BF indicated that the electrode had passed out of the DPD. Iontophoretic deposits of HRP were made near the beginning and end of each electrode penetration, using $1 \mu \mathrm{A}$ positive current for $10 \mathrm{~min}$ (pulsed; $7 \mathrm{sec}$ on, $7 \mathrm{sec}$ off).

The effect of binaural stimulation was assessed by audiovisual means and by spike counts obtained from PST histograms. In either case, the contralateral intensity was set $15 \mathrm{~dB}$ above the contralateral threshold, and the effect of ipsilateral stimulation was examined from $30 \mathrm{~dB}$ below to $30 \mathrm{~dB}$ above the contralateral intensity. The effect of binaural stimulation was either facilitatory, inhibitory, or neutral. Whenever binaural inhibition occurred, we determined the IID at which the response rate decreased by $50 \%$ compared to the response to contralateral sound alone. This particular IID was termed the "inhibitory threshold" of the multiunit response. If the multiunit response displayed a sharp change in response rate over a narrow range of IIDs, both audiovisual and spike count methods yielded a similar estimate of the inhibitory threshold. In such cases, the audiovisual analysis was used for convenience. However, if the IID at which the $50 \%$ response rate occurred could not be estimated easily, we quantitatively determined the inhibitory threshold from spike count data.

In single unit experiments, the BF and thresholds of each single unit were determined audiovisually. PST histograms were obtained to plot the ipsilateral and contralateral rate intensity functions. We then tested IID sensitivity by setting the contralateral intensity $10 \mathrm{~dB}$ above threshold and varying the ipsilateral intensity; PST histograms were collected for a wide range of IID conditions generated in this manner. Binaural properties of 62 single units showing contralateral excitation and ipsilateral suppression (EI units) were analyzed by plotting the spike rate as a function of IID. For these single units, the strength of inhibition was quantified by the particular IID at which the neuron's response fell to $50 \%$ of the value obtained when the contralateral sound was presented alone at $10 \mathrm{~dB}$ above threshold. This IID value was the unit's inhibitory threshold. Whenever possible, the IID sensitivity of EI units was also tested at other contralateral intensity settings in order to examine the effects of changes in stimulus level on IID sensitivity. Successful electrode penetrations were marked by an iontophoretic deposit of HRP at the end of the penetration ( $+1 \mu \mathrm{A}$, pulsed, for $10 \mathrm{~min})$.

\section{Histology}

After deposits of HRP were made, the bat was deeply anesthetized and perfused intracardially with buffered saline and a $4 \%$ glutaraldehyde solution. The fixed brain was blocked in the plane of electrode penetrations and placed in a 30\% sucrose-phosphate buffer solution for 6$8 \mathrm{hr}$. Transverse frozen sections were cut at a thickness of $40 \mu \mathrm{m}$, reacted with diaminobenzidene (LaVail, 1975), and counterstained with cresyl violet. HRP deposits made with the pulsed current source through broken-tipped electrodes were highly reliable, producing dark brown spots 


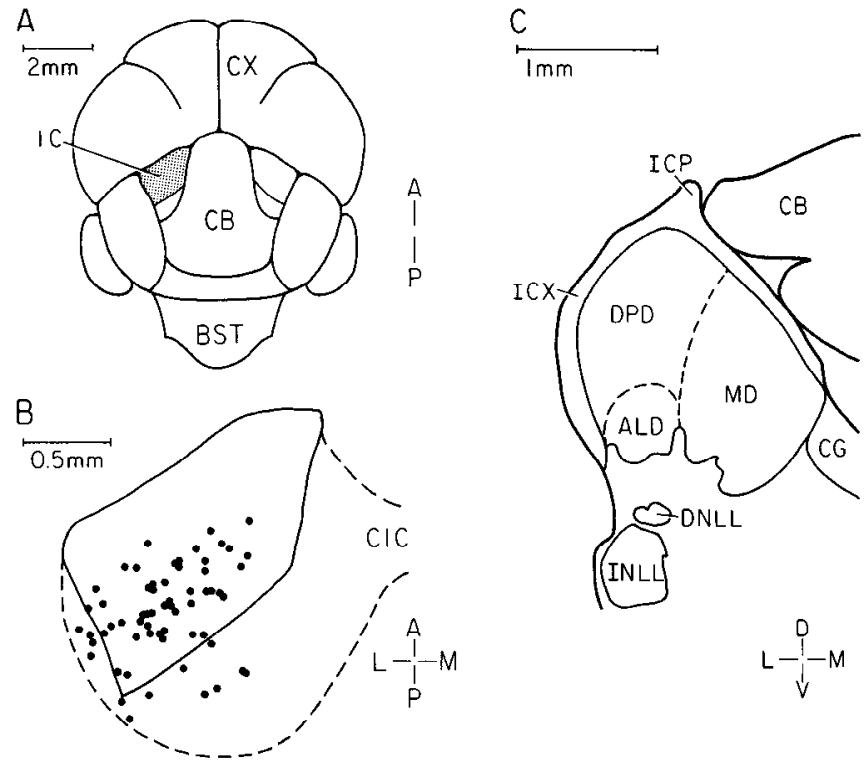

Figure 1. Views of the mustache bat's inferior colliculus (IC). A, View of dorsal surface of the brain from above and slightly posterior. The large $I C$ is visible as the shaded region. $B$, Dorsal view, from the same perspective, of the IC surfacc (solid line) and full outline of the IC (dashed line) seen when the overlying cerebellum is removed. The approximate positions of 62 electrode penetrations from 18 mapping experiments are shown. An additional 15 penetrations from the mapping experiments were not found in the histological sections. $C$, Transverse section through the mustache bat's IC, showing the three divisions of the central nucleus - the $A L D, D P D$, and $M D$. Each division has a discrete frequency representation: The ALD (anterolateral division) contains tonotopically organized responses to frequencies from 10 to 60 $\mathrm{kHz}$; the DPD (dorsoposterior division) contains cells sharply tuned to frequencies between 60 and $64 \mathrm{kHz}$; and the MD (medial division) contains tonotopically organized responses to frequencies from 64 to about $110 \mathrm{kHz}$. This section was located approximately midway between the caudal and rostral poles of the IC. Other abbreviations: $B S T$, brain stcm; $C B$, ccrebellum; $C G$, central gray; $C I C$, commissure of the inferior colliculus; $C X$, cerebral cortex; $D N L L$, dorsal nucleus of the lateral lemniscus; $I C P$, pericentral nucleus of the inferior colliculus; $I C X$, external nucleus of the inferior colliculus; $I N L L$, intermediate nucleus of the lateral lemniscus.

$50-100 \mu \mathrm{m}$ in diameter. Deposits were produced less reliably with single unit electrodes.

The locations of recording sites were reconstructed from the HRP deposits observed in transverse sections. In most cases, both HRP deposits from a penetration were recovered. The distance between the two deposits, read from the microdrive counter, was scaled according to the measured distance in the histological sections. The locations of recording sites along the penetration were then plotted. In some cases, particularly in earlier experiments, one dcposit was recovered. Here, recording sites were plotted by assuming that $0 \mu \mathrm{m}$ on the microdrive counter corresponded to the brain surface, and the locations of units or clusters were scaled according to the depth of the HRP deposit below the surface in the histological material. No adjustment was made for shrinkage of the sections.

\section{Results}

The mustache bat's greatly enlarged IC lies exposed on the dorsal surface of the brain between the cerebellum and cerebral cortex

Table 1. Numerical distribution of binaural classes-multiunit responses

\begin{tabular}{lllll} 
& EO & EE & EI & Total \\
\hline$n$ & 444 & 112 & 279 & 835 \\
& $(53 \%)$ & $(13 \%)$ & $(33 \%)$ & \\
\hline
\end{tabular}

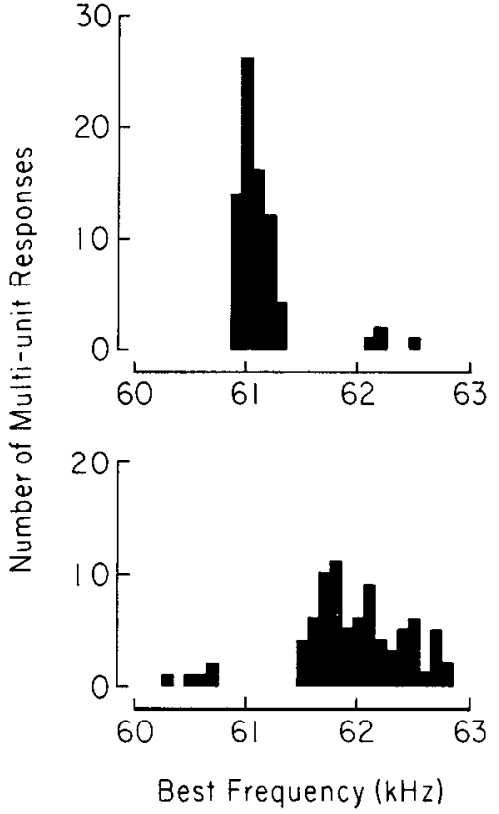

Figure 2. Distribution of best frequencies (BFs) for clusters in the DPD of two mustache bats. This figure shows two extreme cases, in which BFs were most narrowly (top) and most widely (bottom) distributed. $n=76$ and 82 , respectively. BFs were almost always limited to a 0.8 $\mathrm{kHz}$ band within individual bats. The animals used were P6-25-84 (top) and P3-31-83 (bottom).

(Fig. 1A). A large surface blood vessel located just caudal to the IC, running from caudolateral to rostromedial, provided a reliable landmark for the placement of clectrodes. Binaural responses were sampled throughout the DPD and from the surrounding pericentral zone (Fig. $1 B$ ). The initial recording sites in dorsoventral penetrations usually were distinguished either by a lack of responsiveness or by sluggish responses, with broader tuning and generally higher BFs than responses encountered more ventrally. These were most likely in the pericentral nucleus (ICP). In contrast, responses in the central nucleus were brisk and sharply tuned. Auditory responses in the lateral and dorsolateral extremities of the IC, in the external nucleus (ICX) (Zook and Casseday, 1982a; Zook et al., 1985), were similar to those in the ICC.

\section{Tonotopic organization of the ICC}

The tonotopic organization of the ICC observed in these mapping experiments is in agreement with a previous study by Zook et al. (1985). They recognized three divisions of the central nucleus on the basis of cytoarchitecture, neuronal architecture, and physiological recordings. These divisions are the anterolateral division (ALD) representing frequencies below $60 \mathrm{kHz}$, the medial division (MD) representing frequencies above approximately $64 \mathrm{kHz}$, and the dorsoposterior division (DPD) (Fig. $1 C$ ).

The DPD contains neurons tuned to the second harmonic, constant frequency (CF) component of the bat's sonar pulse (Pollak and Bodenhamer, 1981). The extraordinarily sharp tuning of these neurons (average Q10dB value exceeding 100) makes them conspicuous (Pollak and Bodenhamer, 1981). The distribution of BFs of these sharply tuned neurons within the DPD varied among individual bats; the modal BF ranged from 59.5 to $63.7 \mathrm{kHz}$ in our subjects. For most bats, the BFs of single units or clusters were tuned to within a $0.8 \mathrm{kHz}$ band (Fig. 2, top). In a few subjects, the range of BFs for sharply tuned neurons was larger - up to $1.5 \mathrm{kHz}$ (Fig. 2, bottom). In dorsoventral penetrations through the DPD, consecutive multiunit responses 


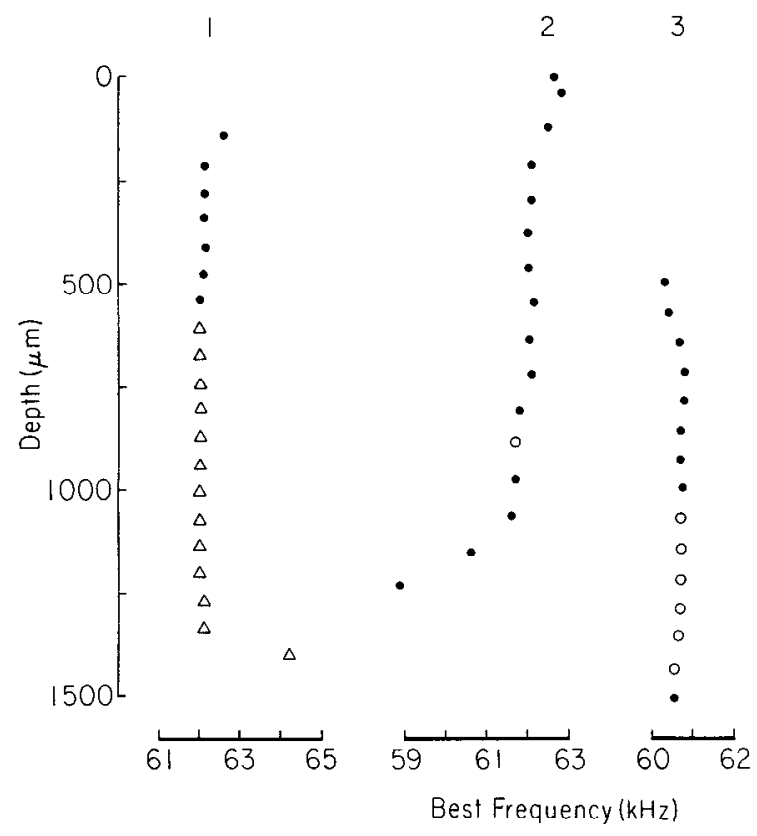

were tuned to very nearly the same frequency, although the BF tended to decrease very slightly with depth (see Figs. 3, 7, and 8 ). The BF changed abruptly when the electrode passed from the DPD into the MD or ALD. These data emphasize that only a very narrow band of frequencies is represented in the DPD.

\section{Classification of binaural responses in the DPD}

The responses of multiunit clusters to dichotic stimulation formed three general categories. EO (monaural) responses were elicited by contralateral sound and were unaffected by ipsilateral sound presented either alone or simultaneously with contralateral sound. EE responses displayed excitatory effects from both ears, as either a monaural response or a binaural facilitation. EI clusters displayed an excitatory response to contralateral stimulation that was suppressed by the simultaneous presentation of ipsilateral sound. Each of the three general categories of binaural response was clearly a heterogeneous group. For example, EE responses were either nonfacilitating (most common) or facilitating, and had a range of threshold disparities for ipsilateral versus contralateral sound. EI responses differed primarily in their sensitivity to IID. A small number of EI clusters (14\%) displayed a very weak excitatory response to ipsilateral sound. Each binaural response pattern has been described at the single unit level in the mustache bat's IC (Fuzessery and Pollak, 1985).

The maximum IID generated by the mustache bat's external ears at $60 \mathrm{kHz}$ is about $30 \mathrm{~dB}$ (Fuzessery and Pollak, 1985). Thus, a cluster was considered to be functionally binaural only if an excitatory or inhibitory effect of ipsilateral sound occurred at IIDs less than $30 \mathrm{~dB}$. The numerical distribution of the three categories is shown in Table 1 . The loci of penetration sites may have biased the percentages in favor of recording $E O$ responses.

\section{Topographic distribution of binaural properties in the DPD}

One of two major findings from our mapping studies is that binaural responses are organized in the DPD. Within individual electrode penetrations, a single binaural class was recorded for several hundred microns (Fig. 3). Of 77 penetrations, $66(86 \%)$ displayed a segregation of binaural responses. Those that did not were usually from the anterior or posterior margins of the DPD, where the response segregation either breaks down or cannot be observed with the penetration angles used. More important, each binaural class was regularly found in specific regions of the DPD. Dorsoventral penetrations arranged in a lat-

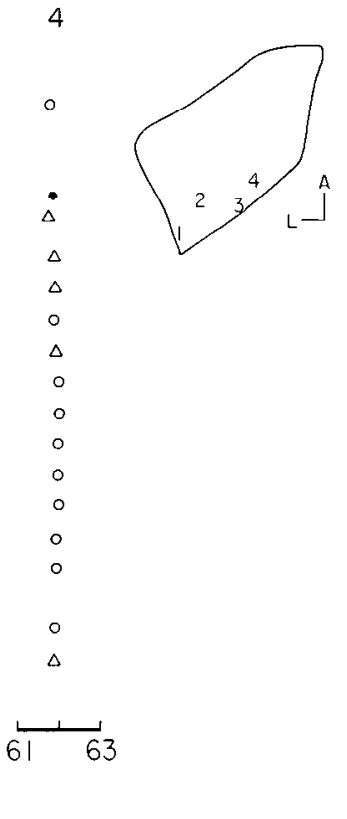

Figure 3. Segregation of binaural responses in penetrations through the DPD. The BFs and binaural classes of multiunit responses are shown in four dorsoventral penetrations. An outline of the dorsal surface of the IC and the locations of the four penetrations are shown in the upper right. Penetrations are from four animals: (1) P12-15-83, (2) P3-31-83, (3) P4-26-84, and (4) P45-84. The increase in BF at the end of penetration 1 occurred because the electrode passed into fibers of the lateral leminiscus. ๑, $\mathrm{EO} ; \mathrm{O}, \mathrm{EI} ; \triangle \mathrm{EE}$. eral-to-medial sequence show general features of this topographic organization (Fig. 3). EI responses were primarily located in the ventromedial part of the DPD (penetrations 3 and 4), while EE responses occured in two regions-ventrolaterally (penetration 1) and dorsomedially (penetration 4). EO responses were found in the dorsal and lateral portions of the DPD (penetrations 13).

Results from four bats illustrate this organization in greater detail (Fig. 4). The binaural organization embodied by each of the penetrations in Figure 4 has been corroborated by other penetrations at nearly the same location. The position of each penetration within the $\mathrm{IC}$ is shown by the point where the electrode penetrated the collicular surface (Fig. 4, dorsal view). In each penetration, only the binaural properties of $60 \mathrm{kHz}$ responses are shown. All three divisions of the ICC are not present at each rostrocaudal level (Fig. 4); in roughly the caudal half of the IC, only the DPD and MD are found. Rostrally, the ALD appears ventral to the DPD in transverse sections.

EI responses, sharply tuned near $60 \mathrm{kHz}$, were consistently found in three regions of the IC. The principal EI region was clearly within the DPD, located in the ventromedial part and extending along the caudal-to-rostral dimension from about 600 to $1300 \mu \mathrm{m}$ (Fig. 4, penetrations A4, B2, B3, D2, and D3). The dorsoventral thickness of this region varied from less than 200 to more than $800 \mu \mathrm{m}$. The region rarely extended more than $1750 \mu \mathrm{m}$ lateral to the midline. Within this EI region, responses varied principally with respect to IID sensitivity, as described below (Properties of $60 \mathrm{kHz}$ EI units and clusters).

The $60 \mathrm{kHz}$ EI responses were also recorded regularly in regions of the IC that apparently were not part of the DPD. Penetrations through the most lateral part of the IC frequently encountered a series of EI responses (e.g., Fig. 4, penetration C1). This region appears to lie in ICX. Another group of EI responses was found in the rostral, dorsolateral part of the IC (Fig. 4, penetration D1). In both of these regions, multiunit responses were sharply tuned to $60 \mathrm{kHz}$ and were usually as brisk as those in the ventromedial EI region of the DPD. Despite these physiological similarities to ICC responses, the locations of these responses suggested that they were part of ICX (Zook and Casseday, 1982a; Zook et al., 1985). In general, it was difficult to delineate the borders between the ICC and pericentral areas using cytoarchitectonic criteria.

$E E$ responses were consistently found in two distinct regions, 

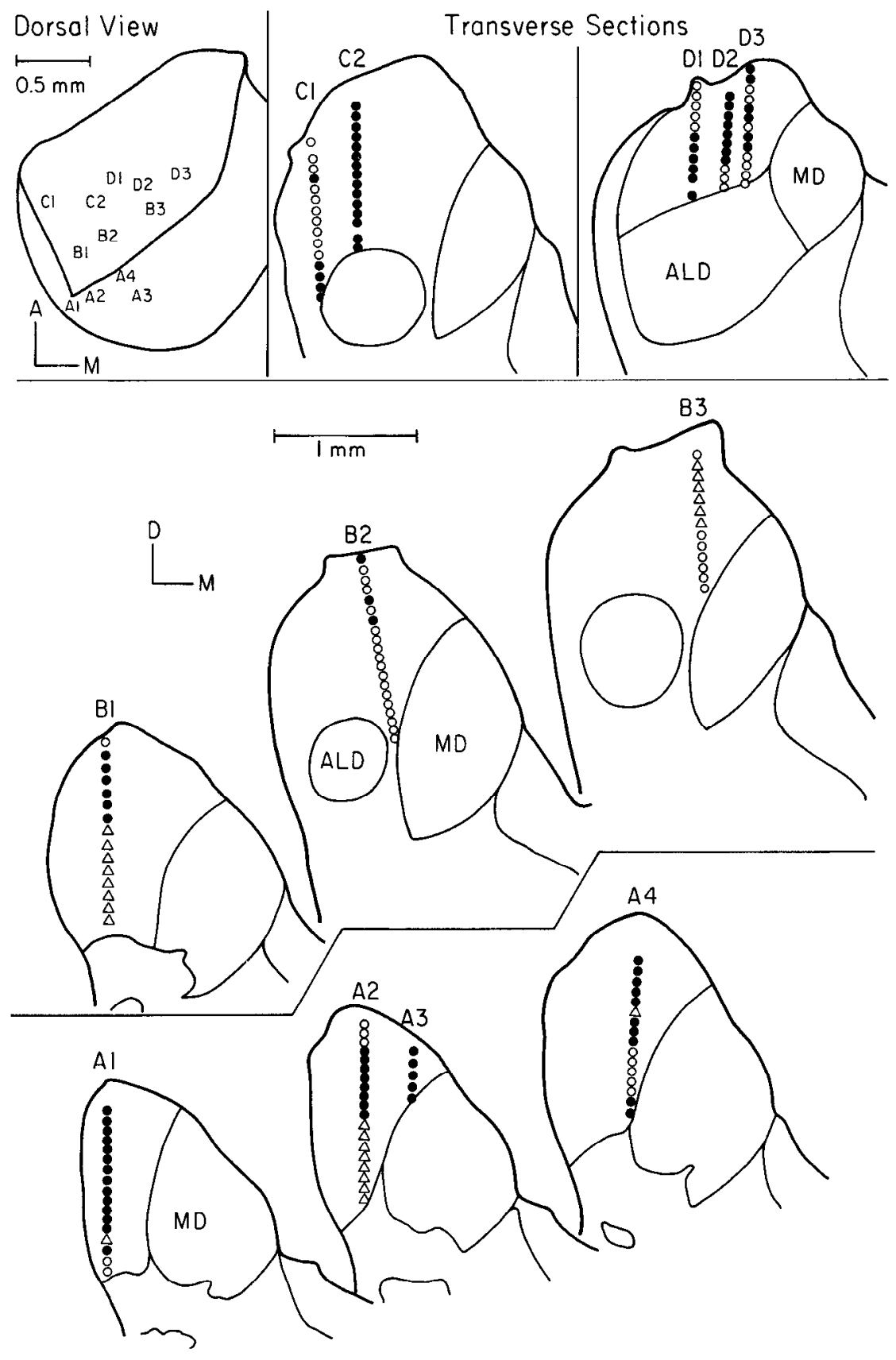

Figure 4. Topographic organization of binaural responses in the DPD. A Dorsal View of the IC in the upper left shows the approximate location of penetrations illustrated in Transverse Sections in the rest of the figure. Results from four animals $(A, \mathrm{P} 5-17-84 ; B$, P419-84; $C, \mathrm{P} 6-25-84 ; D, \mathrm{P} 5-10-84)$ are used to illustrate the binaural response topography. Only the binaural properties of $60 \mathrm{kHz}$ responses, i.e., those within the DPD, are shown. $\mathrm{EO} ; 0$, EI; $\triangle$, EE.

both clearly within the DPD. One was located in the ventrolateral portion of the caudal DPD (Fig. 4, penetrations A2, B1). These two penetrations mark the approximate caudorostral extent of this EE region (from about 400 to $750 \mu \mathrm{m}$ ). All of the EE responses in this group were found at least $1850 \mu \mathrm{m}$ lateral to the midline. The second EE region was found in the dorsomedial DPD, overlying part of the ventromedial EI region (Fig. 4 , penetration $\mathrm{B3}$ ). EE responses within this region were always located within $1550 \mu \mathrm{m}$ of the midline, the region extending from 650 to $1000 \mu \mathrm{m}$ in the caudorostral dimension. The mapping data revealed no physiological distinctions between the two EE regions; each contained multiunits with a range of disparities between ipsilateral and contralateral thresholds, and only a few strongly facilitated responses.

$E O$ responses were found throughout much of the dorsal and lateral DPD. In the caudal-most part, EO responses occurred throughout nearly the entire penetration (Fig. 4, penetration
A1). In somewhat more rostral penetrations (Fig. 4, penetrations A2, A3, A4, B1), EO responses were limited to the dorsal DPD as ventral EE and EI regions expanded in size. Because the ventrolateral EE region extended rostrally only as far as 750 $\mu \mathrm{m}$, more rostral penetrations in the lateral DPD encountered EO responses throughout (Fig. 4, penetration C2). Still more rostrally, EO responses were found overlying the ventromedial EI region (Fig. 4, penetration D2), and ventral to the dorsolateral EI region (Fig. 4, penetration D1)

Each of these regions was clearly dominated by a particular binaural response class. However, we do not wish to imply that the response segregation was complete, since the multiunit technique can mask some of the variability within a cluster. Nevertheless, these regions stood in contrast to other parts of the DPD, where there was no clear segregation of binaural responses. In the rostromedial DPD, binaural responses dorsal to the EI region were usually not segregated, often consisting of both EO 


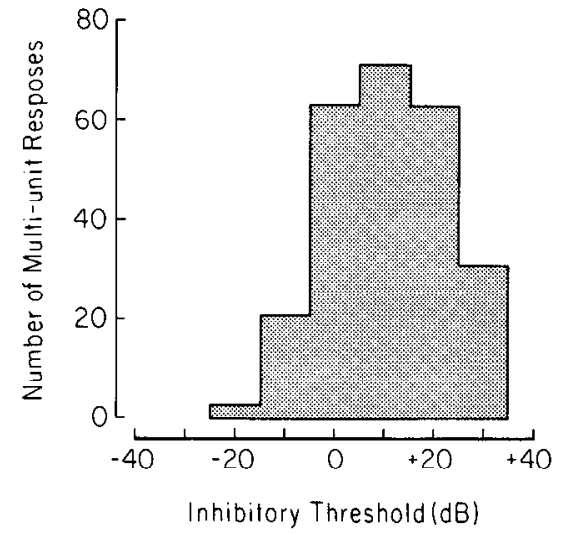

Figure 5. Numerical distribution of the inhibitory thresholds of all sharply tuned, $60 \mathrm{kHz}$ EI multiunit responses in our sample $(n=252)$.

and EI responses (Fig. 4, penetration D3). The caudal DPD was not segregated in all cases; although penetration A3 shows EO responses exclusively, others in nearly the same location yielded combinations of EO and EE clusters.

\section{Properties of $60 \mathrm{kHz}$ EI single units and clusters}

In the mapping experiments, we observed that multiunit EI responses differed in their sensitivity to IIDs (Fig. 5). We characterized this sensitivity by the particular IID required to produce a $50 \%$ suppression of the response rate elicited by the contralateral sound alone at $15 \mathrm{~dB}$ above threshold. This IID was termed the inhibitory threshold. Inhibitory thresholds of multiunit responses were specified to the nearest $5 \mathrm{~dB}$ increment.

We tested the IID sensitivity of EI single units in the DPD to determine if they, like multiunit responses, displayed differences in their inhibitory thresholds. To compare inhibitory thresholds of different EI single units, we used the IID function obtained when the contralateral sound intensity was set $10 \mathrm{~dB}$ above threshold. Thus, in Figure 6, the inhibitory thresholds of three units varied from $-15 \mathrm{~dB}$ (unit $\mathrm{A}$ ) to $+17 \mathrm{~dB}$ (unit $\mathrm{C}$ ), illustrated by the solid line in the IID functions. Note that positive IIDs (and inhibitory thresholds) are those for which the criterion inhibition was elicited when the ipsilateral sound was more intense. The inhibitory thresholds in our sample of single EI units ranged from $-20 \mathrm{~dB}$ to $+30 \mathrm{~dB}$.

We also examined the manner in which the IID functions of single units varied with stimulus level. Changes in stimulus level usually resulted in limited shifts of the IID functions of EI units (Fig. 6). In each of the three units in Figure 6, IID sensitivity was tested at three contralateral levels, spanning a $20 \mathrm{~dB}$ range. The shifts in inhibitory threshold in these units range from -6 $\mathrm{dB}$ for unit $\mathrm{C}$ to $-13 \mathrm{~dB}$ for unit $\mathrm{A}$. Despite these shifts, the IID sensitivity of each of the three units was distinct from the other units throughout the $20 \mathrm{~dB}$ intensity range. Of $21 \mathrm{EI}$ single units tested at more than one intensity setting, most (16) displayed a shift in inhibitory threshold that was less than that shown for unit A in Figure 6. Moreover, this shift in inhibitory threshold was usually in the same direction. That is, most (15) of these single units displayed a lower inhibitory threshold, i.e., a stronger inhibitory effect, at higher stimulus levels (e.g., Fig. 6 , units $A$ and $C$ ). These results suggest that the inhibitory threshold, measured at a specified contralateral level, provides a good characterization of an EI unit's IID sensitivity and permits a comparison of the IID sensitivity of different units.

\section{Topographic organization of IID sensitivity}

Our second major finding concerned the topographic distribution of inhibitory thresholds within the DPD. Dorsoventral penetrations through EI regions displayed different patterns of change

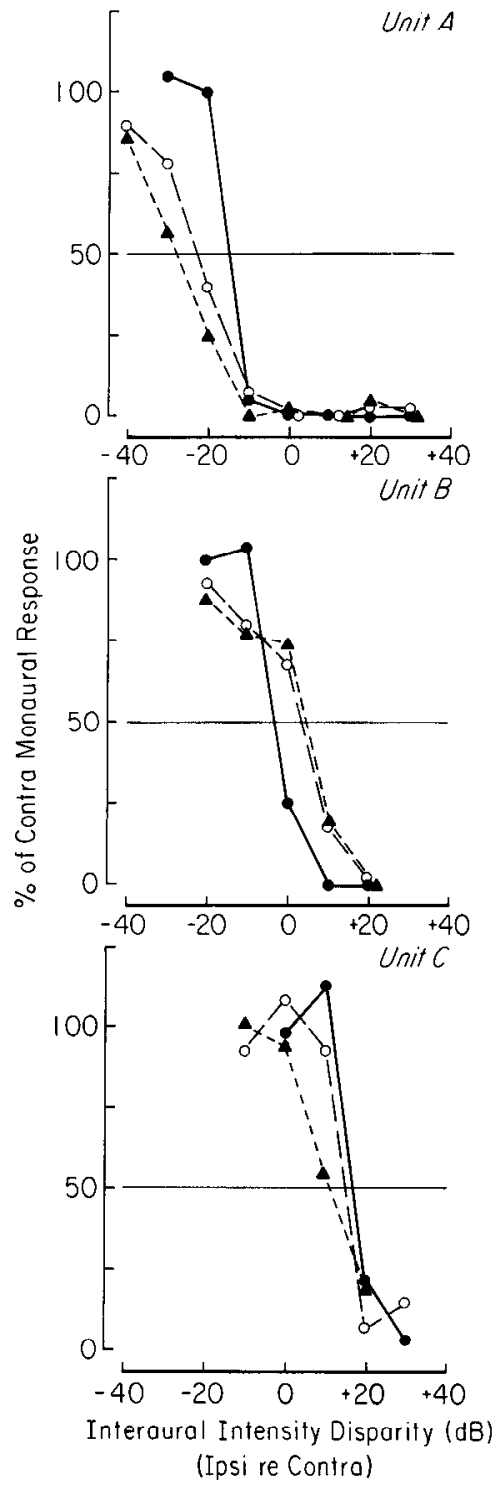

Figure 6. Responses of three EI single units as a function of the IID. The sensitivity to IIDs was measured by holding the contralateral (excitatory) intensity constant and changing the ipsilateral (inhibitory) intensity in $10 \mathrm{~dB}$ steps. Each unit was tested at three contralateral intensity settings $(0,+10 \mathrm{~dB} ; 0,+20 \mathrm{~dB} ; \mathbf{\Delta},+30 \mathrm{~dB})$. The horizontal line at the $50 \%$ response rate indicates the criterion for "inhibitory threshold" - the IID at which the response rate was $50 \%$ of the response to the contralateral sound alone.

in the inhibitory threshold with depth. The most common pattern ( 21 of 37 penetrations) was a systematic decrease in the inhibitory thresholds of clusters with increasing electrode depth (Fig. 7). The more dorsal EI responses had high inhibitory thresholds, i.e., the ipsilateral sound suppressed the excitatory response only if it was 20-30 dB more intense than the contralateral sound. Subsequent EI responses displayed a progressive shift to lower inhibitory thresholds. The most ventral EI responses had the lowest inhibitory thresholds; they were suppressed by ipsilateral sound equal to or less intense than the contralateral sound. In 15 of these penetrations, an inhibitory threshold shift of 20-35 dB was highly correlated with increasing depth $(r<-0.77, p<0.05$; nondirectional Pearson correlation test). In six other penetrations, the inhibitory threshold decreased with depth, but the correlation was not statistically significant (Fig. 8, penetrations 1 and 2). 


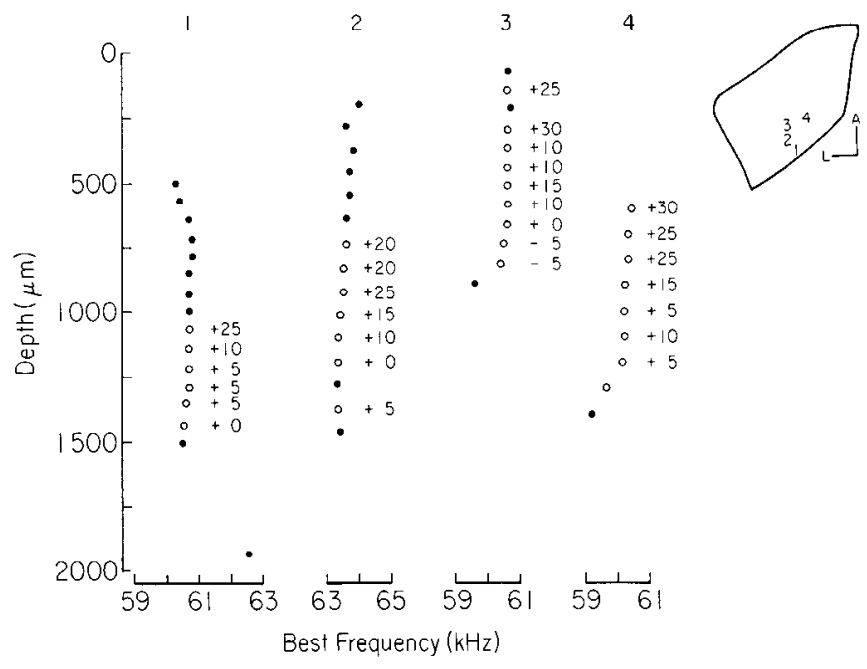

Figure 7. Systematic decrease in the inhibitory thresholds of EI clusters in dorsoventral penetrations through the DPD. The BF, binaural class, and inhibitory threshold (numbers to right of symbols) of multiunit responses are shown in four penetrations. - EO; O, EI. Surface view of the IC indicates the location of penetrations from four animals: (1) P4-26-84, (2) P4-7-83, (3) P8-11-83, and (4) P3-15-83.

This was not the only pattern of change in the inhibitory threshold within penetrations, however. In eight other penetrations, the inhibitory threshold remained virtually unchanged through the EI response region, varying by less than $10 \mathrm{~dB}$ over several hundred microns of EI responses (Fig. 8, penetrations 3 and 4). In four penetrations, different inhibitory thresholds were recorded, but no systematic pattern of change with depth was observed. Five more penetrations contained too few EI responses (less than four) to judge the pattern. These results are summarized in Table 2.

Each EI region could be characterized by a particular topographic pattern of change in the inhibitory threshold (Fig. 9, Table 2). All penetrations displaying a systematic shift in inhibitory thresholds with depth, except one, were located within the ventromedial EI region. Moreover, in this region, those penetrations with systematic inhibitory threshold shifts were grouped within the central portion; the five penetrations of the ventromedial EI region that showed no pattern or no change lay outside of this central part (Fig. 9). These findings show that a topographic organization of IID sensitivity exists in the ventromedial EI region of the DPD, where high inhibitory thresholds are located dorsally and lower inhibitory thresholds more ventrally.

Both the lateral and dorsolateral EI regions, which may be outside of the DPD, displaycd a pattern of IID sensitivity distinctly different from that in the ventromedial region within the

Table 2. Topographic patterns of change in IID sensitivity

\begin{tabular}{llll} 
& \multicolumn{2}{l}{ EI region } & \\
\cline { 2 - 4 } IID pattern & $\begin{array}{l}\text { Ventro- } \\
\text { medial }\end{array}$ & Lateral & $\begin{array}{l}\text { Dorso- } \\
\text { lateral }\end{array}$ \\
\hline Strong decrease & 14 & 0 & 1 \\
Weak decrease & 6 & 0 & 0 \\
No change & 1 & 3 & 4 \\
No pattern & 4 & 0 & 0 \\
Too few responses & 4 & 1 & 0
\end{tabular}

$n=37$ penetrations; one penetration passed through both the dorsolateral and ventromedial EI regions.

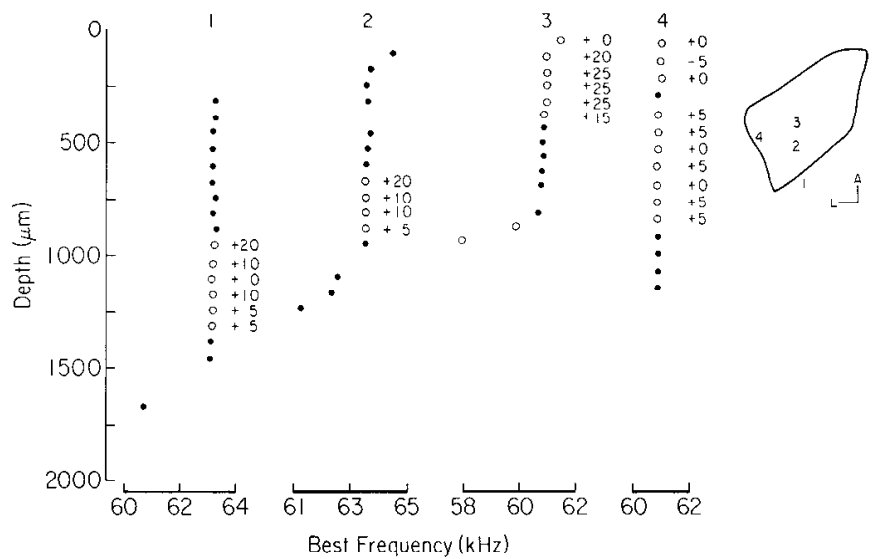

Figure 8 . Different patterns of change in the inhibitory thresholds of EI clusters in dorsoventral penetrations ( $1, E O ; O, E I)$. Penetrations 1 and 2 are examples of correlated shifts in the inhibitory threshold with depth that are not statistically significant. In penetrations 3 and 4 , inhibitory thresholds remained nearly constant with increasing depth. Surface view of the IC indicates the location of penetrations from four animals: (1) P5-17-84, (2) P8-27-84, (3) P5-10-84, and (4) P6-25-84.

DPD. In these two lateral regions, the predominant pattern (seven of eight penetrations) was a constant inhibitory threshold through the EI region (Fig. 9). Only one penetration showed a systematic decrease, and none of the penetrations displayed a nonsystematic inhibitory threshold pattern. We did not sample these regions in sufficient detail to determine if IID sensitivity systematically shifts along some other axis, e.g., the rostrocaudal axis.

It is unlikely that the topographic organization of inhibitory thresholds reported here can be explained by long-term changes in the sensitivity of a bat's auditory system over the course of an experiment. Indeed, we observed no changes in the contralateral excitatory threshold of successive clusters that would account for a systematic shift in inhibitory thresholds. Moreover, systematic shifts were observed over a short period of

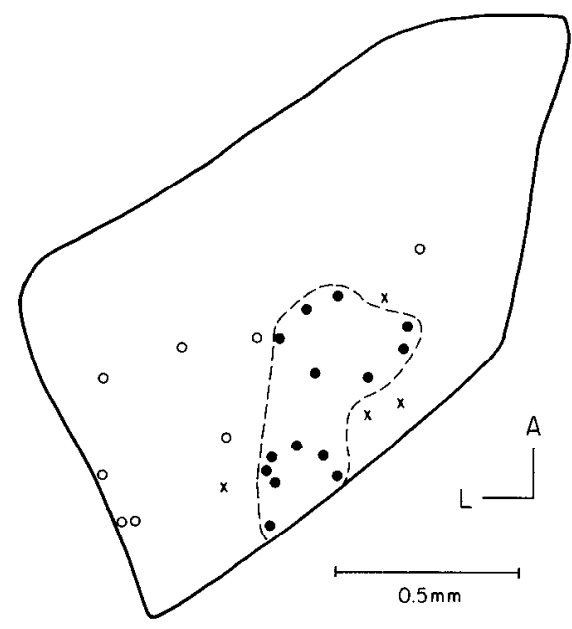

Figure 9. Distribution of EI penetrations with different patterns of change in the IID ( $\bullet$, decreasing IID; $O$, no change; $x$, no pattcrn). EI penetrations with decreasing IID were grouped in the ventromedial portion of the DPD. In this figure, the medial-to-lateral and posteriorto-anterior dimensions of each penetration are those of the EI cluster encountered first, not that found at the surface of the IC. These dimensions could not be determined for six penetrations, which are not included in this figure. Also not included are five penetrations that contained three or fewer EI clusters. 


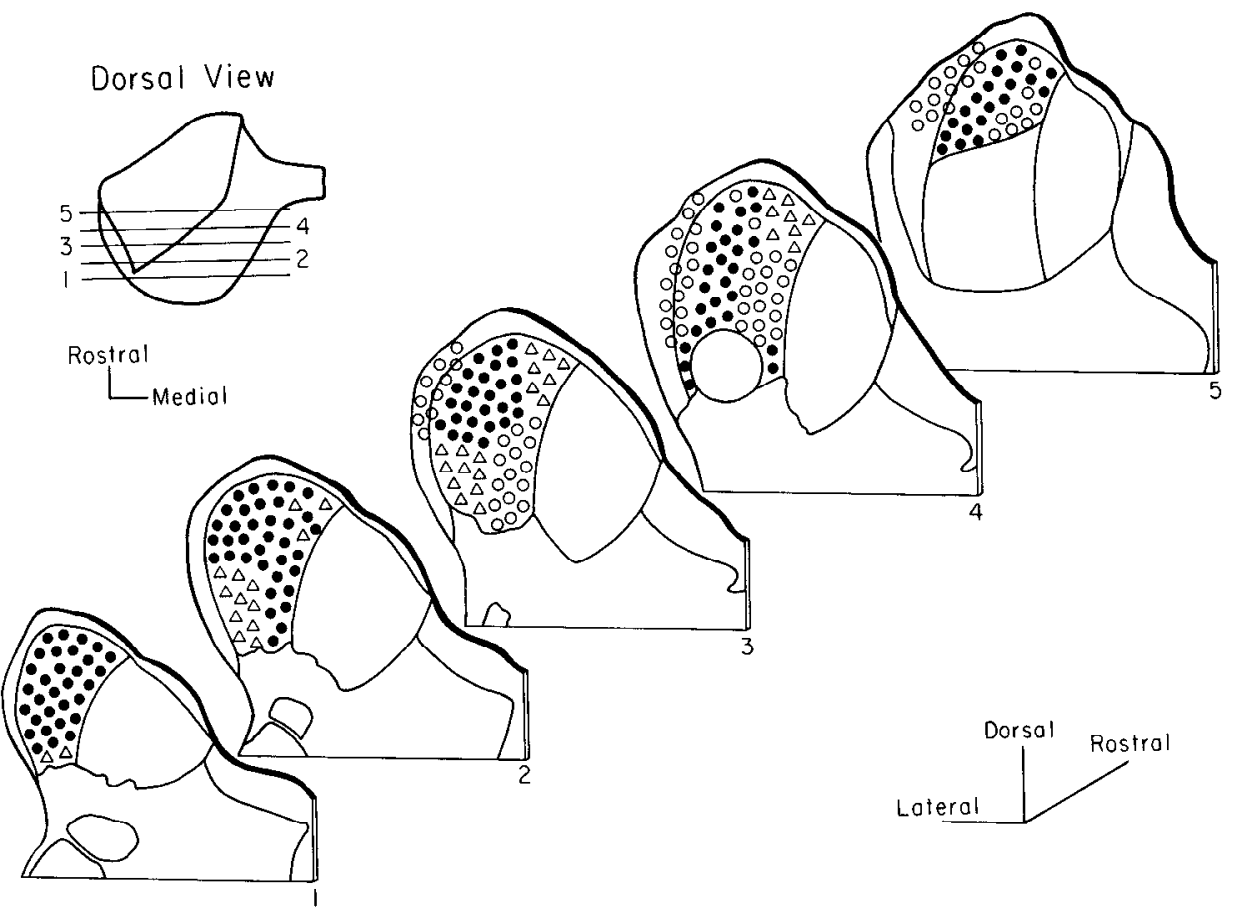

Figure 10. Schematic illustration of the topographic distribution of binaural response classes in the DPD. Symbols $(\Theta, E O ; \triangle, E E ; O, E I)$ indicate binaural regions in the DPD and adjacent ICX in a series of transverse sections separated by $180 \mu \mathrm{m}$.

time, compared with the duration of experiments, and could be obtained within more than one penetration in the same animal. The recording of low inhibitory thresholds at the end of one penetration gave no indication of what inhibitory thresholds might be encountered in the next. Finally, the pattern of change in the inhibitory threshold within a penetration was closely related to the location of that penetration within the IC. These observations provide strong evidence that inhibitory threshold differences within penetrations do not result from changes in the physiological state of one or the other ear. Instead, such shifts are more likely the result of systematic differences in binaural response properties across an EI region.

\section{Discussion}

Two primary results emerge from these studies of the mustache bat's inferior colliculus. First, binaural classes are scgrcgatcd within the $60 \mathrm{kHz}$ region, where four binaural response-specific areas are consistently found (Fig. 10). The organization of binaural responses in the DPD demonstrates that different features of sound are processed separately within one frequency-band representation of the ICC. Moreover, it suggests that brain stem and/or intrinsic projections to this frequency-band region are highly organized.

The second result documents a systematic shift in neural sensitivity to IIDs in the ventromedial EI region within the DPD. EI clusters with high inhibitory thresholds are located dorsally, with a gradual decrease in the inhibitory threshold at more ventral recording sites. This result demonstrates that neurons sensitive to a sound localization cue are systematically organized within a frequency-band representation of the ICC.

In this discussion, we focus on these issues: (1) the DPD as a single frequency-band representation; (2) the organization of binaural properties in the ICC; and (3) the functional implications of an IID organization with respect to the neural representation of space.

\section{Mustache bat's DPD: A frequency-band representation in the ICC}

Aspects of the mustache bat's behavior and auditory system are important in evaluating the specialized nature of the DPD and its usefulness in studies of central auditory processing. This bat navigates and catches prey using a sonar pulse that consists of a fundamental and two to three additional harmonic elements (Novick, 1963). The signal begins with a brief frequency-modulated (FM) upsweep, followed by a long (up to $30 \mathrm{msec}$ ) constant-frequency (CF) component, and ends with an FM downsweep covering about one-half octave. Most energy is contained in the second harmonic CF component, near $60 \mathrm{kHz}$. Echoes of this CF component, returning from the beating wings of insects, contain strong amplitude and frequency modulations. These modulated echoes are probably cues for prey detection and/or identification (Goldman and Henson, 1977; Pollak and Schuller, 1981; Schnitzler and Ostwald, 1983; Schuller, 1979; Suga and Jen, 1977).

The $60 \mathrm{kHz}$ representation throughout the auditory system appcars to be specialized for the fine analysis of these modulation patterns. Two features stand out. First, $60 \mathrm{kHz}$ neurons are very sharply tuned, having $Q 10 \mathrm{~dB}$ values usually exceeding 80 to 100 (Pollak and Bodenhamer, 1981; Suga and Manabe, 1982; Suga et al., 1975). Second, the $60 \mathrm{kHz}$ frequency representation is greatly expanded, occupying roughly onc-third of the ICC (Zook et al., 1985) and primary auditory cortex (Suga and Jen, 1976). Thus, a large population of neurons is available to analyze target features in great detail.

These specialized features appear to originate within the cochlea (Henson, 1978; Leake and Zook, 1985; Pollak et al., 1972; Suga et al., 1975). Higher auditory centers reflect these peripheral specializations but do not appear to be radically different from the same regions in less specialized animals. Thus, the 60 $\mathrm{kHz}$ region in the ICC (the DPD) is similar to other frequencyband representations of the ICC in several respects. For example, the principal morphological cell types (disc-shaped and stellate neurons) are comparable to those in laminated portions of the ICC in the mustache bat (Zook et al., 1985) and in other mammals (FitzPatrick, 1975; Geniec and Morest, 1971; Oliver and Morest, 1984; Rockel and Jones, 1973), although their relative numbers are different. Moreover, the DPD receives a complete set of afferents from the appropriate brain-stem nuclei (Zook and Casseday, 1982b). Finally, it contains the exclusive, albeit expanded, representation within the ICC of a narrow 
frequency band (Zook et al., 1985). These considerations have led Zook et al. (1985) to conclude that the DPD is a hypertrophied version of the classically defined laminae of the ICC (Geniec and Morest, 1971; Morest, 1964; Rockel and Jones, 1973), and lead us to suggest that many of the organizational features found in the DPD may be similar to those in sheetlike frequencyband representations (isofrequency laminae) of the ICC.

\section{Binaural response organization in the $I C$}

Studies of the topographic distribution of binaural responses in cat ICC described a partial segregation of binaural classes; for example, monaural units were clustered in the caudal, lateral, and ventral portions of the nucleus, while units sensitive to the interaural time delay occur in the rostral, dorsal, and lateral ICC (Roth et al., 1978; Semple and Aitkin, 1979). This segregation derives in large part from the functional properties and projection patterns of the brain stem auditory nuclei. These nuclei have particular responses to binaural stimuli. Most neurons in the medial superior olive (MSO) are EE or sensitive to interaural time delays (Goldberg and Brown, 1968; Guinan et al., 1972), while units in the lateral superior olive (LSO) are EI (Boudreau and Tsuchitani, 1968; Guinan et al., 1972). The dorsal nucleus of the lateral lemniscus contains both EE and EI units (Brugge et al., 1970). Monaural input to the ICC is provided by the cochlear nuclei and the ventral nucleus of the lateral lemniscus (Aitkin et al., 1970). These nuclei and their projections form separate channels for the processing of the various dimensions of a sound. A comparable segregation of functional properties has been demonstrated in the barn owl brain stem, where separate time and intensity channels contribute to that animal's auditory space map (Sullivan and Konishi, 1984; Takahashi et al., 1984).

The orderly projections of these nuclei preserve, in part, the segregated processing. Many of the brain stem nuclei do not project to the entire ICC, but terminate within limited zones (Brunso-Bechtold et al., 1981; Henkel and Spangler, 1983; Oliver, 1984; Roth et al., 1978; Zook and Casseday, 1985). In some parts of the ICC, there is a close agreement between the brain stem source of input and the dominant binaural response class. Thus the caudal ICC, dominated by monaural responses (Roth et al., 1978; Semple and Aitkin, 1979), primarily receives projections from the contralateral cochlear nucleus (Brunso-Bechtold et al., 1981; Roth et al., 1978). The low-frequency portion of MSO, containing delay-sensitive neurons, projects to the dorsolateral part of the ICC in cats (Aitkin and Schuck, 1985; Brunso-Bechtold, 1981; Henkel and Spangler, 1983) where most units are delay-sensitive (Kuwada and Yin, 1983; Roth et al., 1978; Semple and Aitkin, 1979). These and other points of agreement provide evidence that binaural response-specific regions in the ICC reflect the binaural pattern of the principal brain stem input to that region. There may be exceptions, however; a region containing many EE units apparently does not receive projections from the most likely source of EE input, the MSO (Henkel and Spangler, 1983; Semple and Aitkin, 1979).

What is the result of superimposing the organization of binaural responses onto the laminar organization of frequencyband representations in the ICC? The studies of Roth et al. (1978) and Semple and Aitkin (1979) describe electrode penetrations in which a series of units at nearly the same BF belonged to the same binaural response class. They show that a welldefined segregation of binaural properties occurs within individual frequency-band laminae. Our results in the DPD corroborate those findings. Binaural properties are segregated throughout most of the DPD in a complex topography, involving at least four binaural response-specific regions.

It is reasonable to expect that the binaural response organization in the ICC is maintained in some form within the ascending projection to the ventral division of the medial genic- ulate body (MGv). However, there is only a poor understanding of how ICC projections of specific binaural regions terminate in $\mathrm{MGv}$, and physiological studies of this region have not found a clear organization of binaural responses (Calford and Webster, 1981). Yet, the principal target of MGv projections, primary auditory cortex, does contain an organization of binaural responses within frequency-band representations in the mustache bat (Manabe et al., 1978) and cat (Imig and Adrian, 1977; Middlebrooks et al., 1980). Moreover, the sources of ascending projections to EI and EE regions of frequency-band representations in cat $\mathrm{AI}$ are segregated within MGv (Middlebrooks and Zook, 1983). Thus, an orderly projection of ICC efferents, in which binaural response properties are segregated within frequencyband representations, may underlie a similar but modified organization within $\mathrm{MGv}$ and primary auditory cortex.

We have described a functionally defined organization of the DPD based on one set of criteria - the response to binaural stimuli. Other response features, such as sensitivity to signal modulations, may be organized within or across these binaural regions. We do not expect a full congruence between this physiological map based on one response criterion and anatomical parcellation schemes based on architectonic or connectional criteria. For example, a given binaural region may be composed of subdivisions with different afferents or efferents, or may receive afferents that differ from the prevailing binaural type (see Oliver, 1984). One contribution of this study is the definition of the physiological organization within a single frequency-band representation, which can serve as a basis for functional/anatomical studies examining the relationship between physiological properties of the ICC and its inputs, intrinsic connections, and outputs.

Topographic organization of IID sensitivity in the DPD: Neural correlate of a frequency-band analysis of a sound localization cue

The orderly representation of IID sensitivity within the primary auditory pathway is a new finding. It is unclear whether this organization arises within the DPD through the interaction of more than one input, or whether it reflects an organization present in one of the brain stem projections, for example, the contralateral LSO. There are, however, reasons to suspect that this is not an exclusive feature of the DPD. We have recently obtained evidence suggesting that a topographic organization of IID sensitivity also exists in frequency-band laminae from another division of the mustache bat's ICC (Wenstrup et al., 1985b). Moreover, a similar organization of IID sensitivity has been reported in the cat superior colliculus (Irvine and Wise, 1983). Finally, EI populations containing different IID sensitivities, a prerequisite for an IID organization, have been described in cat LSO (Boudreau and Tsuchitani, 1968), ICC (Moore and Irvine, 1981), and auditory cortex (Phillips and Irvine, 1981). Although this evidence is not conclusive, it suggests that a systematic representation of IID sensitivity may be common in the auditory system.

The organization of IIDs in the DPD has two functional implications for the neural encoding of sound location at the level of the ICC: (1) sound localization cues are systematically represented, and (2) such representation occurs within frequencyband laminae.

How does the pattern of activity in a topographically organized population of EI neurons in the DPD reflect the position of a sound in space? Recent studies of $60 \mathrm{kHz}$ EI neurons in the mustache bat show how binaural properties and ear directionality contribute to the spatial selectivity of these neurons (Fuzessery and Pollak, 1985; Fuzessery et al., 1985). At $60 \mathrm{kHz}$, the mustache bat's ears are most sensitive to sounds on the horizontal midline and $25^{\circ}-40^{\circ}$ away from the vertical midline. The greatest IIDs (25-30 dB) generated by the ears are located 
in approximately the same position. As a result of these directional properties of the ear, all $60 \mathrm{kHz}$ EI neurons, regardless of IID sensitivity, are most sensitive in the contralateral sound field, $25^{\circ}-40^{\circ}$ off the vertical midline. The IID sensitivity of these neurons primarily influences the location of their receptive field borders. These borders shift systematically from the ipsilateral to the contralateral field for neurons with successively lower inhibitory thresholds (Fuzessery and Pollak, 1985).

Because a neuron's spatial receptive field depends on its IID sensitivity, and because IID sensitivity is topographically organized, the locus of active EI neurons in the DPD therefore depends on the location of a sound source in space, as shown schematically in Figure 11. A sound originating within the ipsilateral field, $25^{\circ}-40^{\circ}$ from the vertical midline, should activate only the dorsal-most EI neurons, those with high inhibitory thresholds. Other cells should be suppressed because inhibitory influences are favored for sounds originating at these locations (Fig. 11, +15 dB). As the sound source moves closer to the vertical midline, the population of active neurons should spread ventrally. A sound located contralateral to the midline should activate nearly all EI neurons; only the most ventral units, with large negative inhibitory thresholds, should be suppressed (Fig. $11,-15 \mathrm{~dB})$. Finally, a sound located $25^{\circ}-40^{\circ}$ into the contralateral field should activate all EI neurons. Thus, the value of the IID of a $60 \mathrm{kHz}$ stimulus may be represented as a systematic, topographic pattern of activity in the EI region of the DPD.

Our results suggest that an IID-dependent pattern of activity occurs within the DPD; a similar representation of the IID values in sounds may take place simultaneously in other frequency-band laminae of the ICC (Wenstrup et al., 1985b). Indeed, accurate sound localization apparently requires that IID cues be analyzed within frequency bands. The directionality, and hence the pattern of IIDs, created by the ears is frequencydependent (e.g., Blauert, 1983; Middlebrooks and Pettigrew, 1981; Phillips et al., 1982; Shaw, 1974), so these cues must be analyzed within frequency bands to avoid ambiguity. Moreover, directionality and IID patterns that differ across frequency bands, i.e., spectral cues, are important for accurate horizontal and vertical sound localization (Fuzessery and Pollak, 1985; Grinnell and Grinnell, 1965; Hebrank and Wright, 1974; Knudsen, 1980; Musicant and Butler, 1985; Pumphrey, 1948).

A variety of other evidence suggests that information related to sound localization is processed within frequency bands. In recent lesion/behavior experiments, small unilateral lesions of cat primary auditory cortex result in sound localization deficits that are restricted to frequencies represented within the lesioned site (Jenkins and Merzenich, 1984). In psychoacoustic studies, human subjects listening in dichotic conditions can lateralize sounds to the left or right as a single fused acoustic image if the appropriate interaural time or intensity cues are presented. Within a limited range, differences in the frequency of the signals to the two ears have no effect on these lateralization judgements. However, when the frequency difference exceeds a certain value, i.e., a critical bandwidth, both lateralization ability and the fusion of the image are degraded (Nuetzl and Hafter, 1981; Perrott and Barry, 1969; Scharf et al., 1976). Each of these results provides strong evidence that cues related to sound localization are analyzed within frequency bands. Our findings suggest a neural correlate for this analysis, by showing how a binaural cue is systematically represented within a frequency-band representation of the IC.

We propose this organization of EI neurons as one component of the analysis of sound localization cues within a frequencyband representation. We have focused on EI neurons because they were easily accessible and displayed a topographically ordered shift in response properties. Other binaural units, particularly those that are strongly facilitated, are also likely to play a role in sound localization, since they are highly selective for
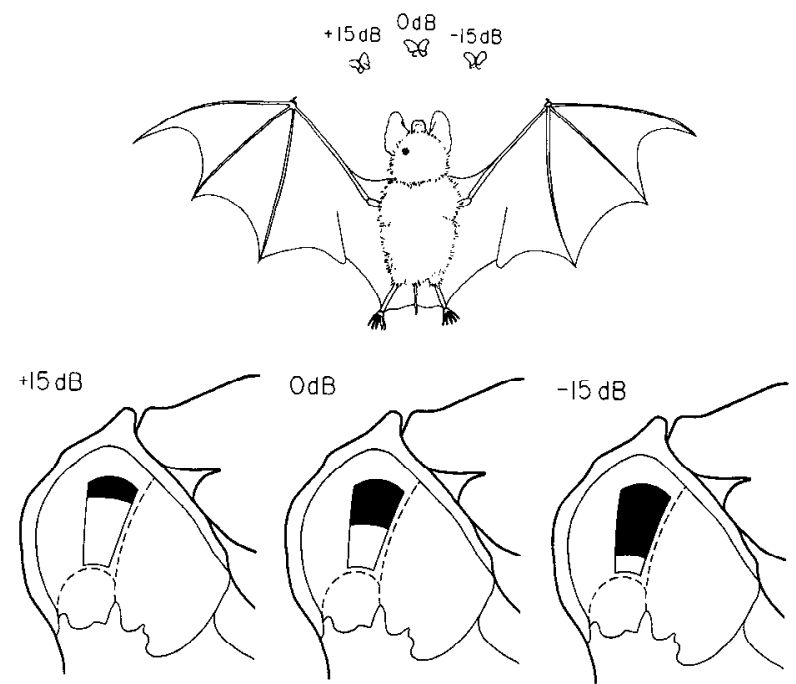

Figure 11. Schematic illustration of the relationship between the IID value produced by a sound source at a given location (moths at top of figure) and the pattern of activity in the ventromedial EI region of the DPD, where IID sensitivity is topographically organized. The activity in this region, indicated by the blackened area, spreads ventrally as a sound source moves from the ipsilateral to the contralateral sound field.

the location of a sound source (Fuzessery and Pollak, 1985; Phillips and Irvine, 1981; Wise and Irvine, 1984; Stillman, 1972). However, our sample of EE multiunit recordings revealed few strongly facilitated binaural cells, and consequently, we found no orderly arrangement of their properties.

\section{Representation of space in the auditory system}

Irvine and Wise (1983) have reported a systematic shift in IID sensitivity in the deeper layers of the cat's superior colliculus (SC). Because SC receives indirect projections from ICC (Edwards et al., 1979; Kudo and Niimi, 1980), it is possible that the shift in IID sensitivity within SC derives from organizational features in ICC similar to that described in this report. Despite the similarities between our results and those of Irvine and Wise, there appear to be significant differences in the manner in which the primary auditory pathway (including the ICC) and the SC encode the location of sounds.

The SC contains a single representation of auditory space (Gordon, 1973; King and Palmer, 1983; Knudsen, 1982; Middlebrooks and Knudsen, 1984), but no orderly representation of sound frequency (Hirsch et al., 1985; Wise and Irvine, 1983). In cats, the results of free-field studies (Gordon, 1973; Middlebrooks and Knudsen, 1984) suggest that at least part of the auditory space map in the SC derives from the organization of binaural properties revealed in dichotic studies (Irvine and Wise, 1983). This IID organization is constructed from both EI and binaurally facilitated neurons. The ear's frequency-dependent directional properties appear to contribute to this space map (Palmer and King, 1985), but that contribution is poorly understood in view of the general lack of frequency selectivity exhibited by auditory neurons in SC. A neural map of auditory space is consistent with the widely presumed functions of the SC in sound localization; it provides topographically ordered instructions to appropriate muscle groups, resulting in orientation movements to novel stimuli (for reviews, see Huerta and Harting, 1984; Stein, 1984).

It is improbable that such a space map exists within the primary auditory pathway. Indeed, studies of both the ICC and auditory cortex find no map (Middlebrooks and Pettigrew, 1981; Moore et al., 1984; Semple et al., 1983). Rather, organization of neural responses according to sound frequency and binaural 
class is the hallmark of this pathway. Despite the absence of an auditory space map, the primary auditory pathway appears to contain an orderly representation of the cues used to derive spatial location. The tonotopic organization provides an initial segregation of frequency-dependent sound localization cues. Superimposed on the tonotopy is a segregation of the different classes of binaural response. Our results, furthermore, suggest that binaural cues for sound localization are topographically organized within binaural response-specific regions of individual frequency-band representations.

\section{References}

Adams, J. C. (1979) Ascending projections to the inferior colliculus. J. Comp. Neurol. 183: 519-538.

Aitkin, L. M., and S. C. Phillips (1984) Is the inferior colliculus an obligatory relay in the cat auditory system? Neurosci. Lett. 44: 259264.

Aitkin, L. M., and D. Schuck (1985) Low frequency neurons in the lateral central nucleus of the cat inferior colliculus receive their input predominantly from the medial superior olive. Hear. Res. 17: 87-93.

Aitkin, L. M., D. J. Anderson, and J. F. Brugge (1970) Tonotopic organization and discharge characteristics of single neurons in nuclei of the lateral lemniscus of the cat. J. Neurophysiol. 33: 421-440.

Aitkin, L. M., S. Fryman, D. W. Blake, and W. R. Webster (1972) Responses of neurones in the rabbit inferior colliculus. I. Frequencyspecificity and topographic arrangements. Brain Res. 47: 77-90.

Beyerl, B. D. (1978) Afferent projections to the central nucleus of the inferior colliculus of the rat. Brain Res. 145: 209-223.

Blauert, J. (1983) Spatial Hearing, MIT Press, Cambridge, MA.

Boudreau, J. C., and C. Tsuchitani (1968) Binaural interaction in the cat superior olive s-segment. J. Neurophysiol. 31: 442-454.

Brugge, J. F., D. J. Anderson, and L. M. Aitkin (1970) Response of neurons in dorsal nucleus of the lateral lemniscus of the cat to binaural tonal stimulation. J. Neurophysiol. 33: 441-458.

Brunso-Bechtold, J. K., G. C. Thompson, and R. B. Masterton (1981) HRP study of the organization of auditory afferents ascending to central nucleus of inferior colliculus in cat. J. Comp. Neurol. 197: 705-722.

Calford, M. B., and W. R. Webster (1981) Auditory representation within principal divison of cat medial geniculate body: An electrophysiological study. J. Neurophysiol. 45: 1013-1028.

Clopton, B. M., and J. A. Winfield (1973) Tonotopic organization in the inferior colliculus of rat. Brain Res. 56: 355-358.

Edwards, S. B., C. L. Ginsburgh, C. K. Henkel, and B. E. Stein (1979) Sources of subcortical projections to the superior colliculus in the cat J. Comp. Neurol. 184: 309-330.

FitzPatrick, K. A. (1975) Cellular architecture and topographic organization of the inferior colliculus of the squirrel monkey. J. Comp. Neurol. 164: 185-208.

Fuzessery, Z. M., and G. D. Pollak (1985) Determinants of sound location selectivity in the bat inferior colliculus: A combined dichotic and free-field stimulation study. J. Neurophysiol. 54: 757-781.

Fuzessery, Z. M., J. J. Wenstrup, and G. D. Pollak (1985) A representation of horizontal sound location in the inferior colliculus of the mustache bat (Pteronotus p. parnellii). Hear. Res. 20: 85-89.

Geniec, P., and D. K. Morest (1971) The neuronal architecture of the human posterior colliculus. Acta Otolaryng. (Stockh.) (Suppl.) 295: $1-33$.

Goldberg, J. M., and P. B. Brown (1968) Functional organization of the dog superior olivary complex: An anatomical and electrophysiological study. J. Neurophysiol. 31: 639-656.

Goldberg, J. M., and R. Y. Moore (1967) Ascending projections of the lateral lemniscus in the cat and monkey. J. Comp. Neurol. 129: 143-156.

Goldman, L. J., and O. W. Henson, Jr. (1977) Prey recognition and selection by the constant frequency bat, Pteronotus p. parnellii. Behav. Ecol. Sociobiol. 2: 411-419.

Gordon, B. (1973) Receptive fields in deep layers of cat superior colliculus. J. Neurophysiol. 36: 157-178.

Grinnell, A. D., and V. S. Grinnell (1965) Neural correlates of vertical localization by echolocating bats. J. Physiol. (Lond.) 181: 830-851.

Guinan, J. J., Jr., B. E. Norris, and S. S. Guinan (1972) Single auditory units in the superior olivary complex: II. Locations of unit categories and tonotopic organization. Intern. J. Neurosci. 4: 147-166.
Hebrank, J., and D. Wright (1974) Spectral cues used in the localization of sound sources on the medial plane. J. Acoust. Soc. Am. 56: 1829-1834.

Henkel, C. K., and K. M. Spangler (1983) Organization of the efferent projections of the medial superior olivary nucleus in the cat as revealed by HRP and autoradiographic tracing methods. J. Comp. Neurol. 221: 416-428.

Henson, M. M. (1978) The basilar membrane of the bat, Pteronotus p. parnellii. Am. J. Anat. 153: 143-158.

Hirsch, J. A., J. C. K. Chan, and T. C. T. Yin (1985) Responses of neurons in the cat's superior colliculus to acoustic stimuli. I. Monaural and binaural response properties. J. Neurophysiol. 53: 726-745.

Huerta, M. F., and J. K. Harting (1984) The mammalian superior colliculus: Studies of its morphology and connections. In Comparative Neurology of the Optic Tectum, H. Vanegas, ed., pp. 687-773, Plenum, New York.

Imig, T. J., and H. O. Adrian (1977) Binaural columns in the primary field (AI) of cat auditory cortex. Brain Res. 138: 241-257.

Irvine, D. R. F., and L. Z. Wise (1983) Topographic organization of interaural-intensity-difference sensitivity and the representation of auditory azimuthal location in the deep layers of the superior colliculus. In Mechanisms of Hearing, W. R. Webster and L. M. Aitkin, eds., pp. 101-106, Monash U. P., Clayton, Australia.

Jenkins, W. M., and M. M. Merzenich (1984) Role of cat primary auditory cortex for sound-localization behavior. J. Neurophysiol. 52: 819-847.

King, A. J., and A. R. Palmer (1983) Cells responsive to free-field auditory stimuli in guinea-pig superior colliculus: Distribution and response properties. J. Physiol. (Lond.) 342: 361-381.

Knudsen, E. I. (1980) Sound localization in birds. In Comparative Studies of Hearing in Vertebrates, A. N. Popper and R. R. Fay, eds., pp. 289-323, Springer-Verlag, New York.

Knudsen, E. I. (1982) Auditory and visual maps of space in the optic tectum of the owl. J. Neurosci. 2: 1177-1194.

Kudo, M., and K. Niimi (1980) Ascending projections of the inferior colliculus in the cat: An autoradiographic study. J. Comp. Neurol. 191: 545-556.

Kuwada, S., and T. C. T. Yin (1983) Binaural interaction in lowfrequency neurons in inferior colliculus of the cat. I. Effects of long interaural delays, intensity, and repetition rate on interaural delay function. J. Neurophysiol. 50: 981-999.

LaVail, J. H. (1975) Retrograde cell degeneration and retrograde transport techniques. In The Use of Axonal Transport for Studies of Neural Connectivity, W. M. Cowan and M. Cuenod, eds., pp. 218-248, Elsevier, New York.

Leake, P., and J. M. Zook (1985) Demonstration of an acoustic fovea in the mustache bat, Pteronotus p. parnellii. Abstract 32. Eighth midwinter meeting of the Association for Research in Otolaryngology,

Manabe, T., N. Suga, and J. Ostwald (1978) Aural representation in the Doppler-shifted-CF processing area of the auditory cortex of the mustache bat. Science 200: 339-342.

Merzenich, M. M., and M. D. Reid (1974) Representation of the cochlea within the inferior colliculus of the cat. Brain Res. 77: 397415.

Middlebrooks, J. C., and E. I. Knudsen (1984) A neural code for auditory space in the cat's superior colliculus. J. Neurosci. 4: 26212634.

Middlebrooks, J. C., and J. D. Pettigrew (1981) Functional classes of neurons in primary auditory cortex of the cat distinguished by sensitivity to sound location. J. Neurosci. $1: 107-120$.

Middlebrooks, J. C., and J. M. Zook (1983) Intrinsic organization of the cat's medial geniculate body identified hy projections to binaural response-specific bands in the primary auditory cortex. J. Neurosci. 3: 203-224.

Middlebrooks, J. C., R. W. Dykes, and M. M. Merzenich (1980) Binaural response specific bands in primary auditory cortex (AI) of the cat: Topographical organization orthogonal to isofrequency contours. Brain Res. 181: 31-48.

Moore, D. R., and D. R. F. Irvine (1981) Development of responses to acoustic interaural intensity differences in the cat inferior colliculus. Exp. Brain Res. 41: 301-309.

Moore, D. R., M. E. Hutchings, P. D. Addison, M. N. Semple, and L. M. Aitkin (1984) Properties of spatial receptive fields in the central nucleus of the cat inferior colliculus. II. Stimulus intensity effects. Hear. Res. 13: 175-188. 
Morest, D. K. (1964) The laminar structure of the inferior colliculus of the cat. Anat. Rec. 148: 314.

Musicant, A. D., and R. A. Butler (1985) Influence of monaural spectral cues on binaural localization. J. Acoust. Soc. Am. 77: 202-208.

Novick, A. (1963) Orientation in neotropical bats. II. Phyllostomatidae and Desmodontidae. J. Mammal. 44: 44-56.

Nuetzl, J. M., and E. R. Hafter (1981) Discrimination of interaural delays in complex waveforms: Spectral effects. J. Acoust. Soc. Am. 69: $1112-1118$

Oliver, D. L. (1984) Dorsal cochlear nucleus projections to the inferior colliculus in the cat: A light and electron microscopic study. J. Comp. Neurol. 224: 155-172.

Oliver, D. L., and D. K. Morest (1984) The central nucleus of the inferior colliculus in the cat. J. Comp. Neurol. 222: 237-264.

Palmer, . R. R., and A. J. King (1985) $\Lambda$ monaural space map in the guinea-pig superior colliculus. Hear. Res. 17: 267-280.

Perrott, D. R., and S. H. Barry (1969) Binaural fusion. J. Aud. Res. 3: 263-269.

Phillips, D. P., and D. R. F. Irvine (1981) Responses of single neurons in physiologically defined area AI of cat cerebral cortex: Sensitivity to interaural intensity differences. Hear. Res. 4: 299-307.

Phillips, D. P., M. B. Calford, J. D. Pettigrew, L. M. Aitkin, and M. N. Semple (1982) Directionality of sound pressure transformation at the cat's pinna. Hear. Res. 8: 13-28.

Pollak, G. D., and R. D. Bodenhamer (1981) Specialized characteristics of single units in inferior colliculus of mustache bat: Frequency representation, tuning, and discharge patterns. J. Neurophysiol. 46: 605-619.

Pollak, G. D., and G. Schuller (1981) Tonotopic organization and encoding features of single units in inferior colliculus of horseshoe bats: Functional implications for prey identification. J. Neurophysiol. 45: 208-226.

Pollak, G., O. W. Henson, Jr., and A. Novick (1972) Cochlear microphonic audiograms in the "pure tone" bat, Chylonycteris parnellii parnellii. Science 176: 66-68.

Pumphrey, R. J. (1948) The sense organs of birds. Ibis 90: 171-199.

Rockel, A. J., and E. G. Jones (1973) The neuronal organization of the inferior colliculus of the adult cat. I. The central nucleus. J. Comp. Neurol. 147: 11-60.

Rose, J. F., R. Galambos, and J. R. Hughes (1959) Microelectrode studies of the cochlear nuclei of the cat. Bull. Johns Hopkins Hosp. 104: 211-251.

Rose, J. E., D. D. Greenwood, J. M. Goldberg, and J. E. Hind (1963) Some discharge characteristics of single neurons in the inferior colliculus of the cat: I. Tonotopical organization, relation of spike-counts to tone intensity, and firing patterns of single elements. J. Neurophysiol. 26: 294-320.

Rose, J. E., N. B. Gross, C. D. Geisler, and J. E. Hind (1966) Some neural mechanisms in the inferior colliculus of the cat which may be relevant to localization of a sound source. J. Neurophysiol. 29: 288314.

Ross, L. S., J. J. Wenstrup, and G. D. Pollak (1983) Aural representation within an isofrequency lamina of the mustache bat's inferior colliculus. Soc. Neurosci. Abstr. 9: 767.

Roth, G. L., L. M. Aitkin, R. A. Andersen, and M. M. Merzenich (1978) Some features of the spatial organization of the central nucleus of the inferior colliculus of the cat. J. Comp. Neurol. 182: 661-680.

Scharf, B., M. Florentine, and C. H. Meiselman (1976) Critical band in auditory lateralization. Sens. Proc. 1: 109-126.

Schnitzler, H.-U., and J. Ostwald (1983) Adaptations for the detection of fluttering insects by echolocation in horseshoe bats. In Advances in Vertebrate Neuroethology, J.-P. Ewert, R. R. Capranica, and D. J. Ingle, eds., pp. 801-827, Plenum, New York.

Schuller, G. (1979) Coding of small sinusoidal frequency and amplitude modulations in the inferior colliculus of 'CF-FM' bat, Rhinolophus ferrumequinum. Exp. Brain Res. 34: 117-132.

Schweizer, H. (1981) The connections of the inferior colliculus and the organization of the brainstem auditory system in the greater horseshoe bat (Rhinolophus ferrumequinum). J. Comp. Neurol. 201: 2549.
Semnle, M. N., and L. M. Aitkin (1979) Representation of sound frequency and laterality by units in central nucleus of cat inferior colliculus. J. Neurophysiol. 42: 1626-1639.

Semple, M. N., L. M. Aitkin, M. B. Calford, J. D. Pettigrew, and D. P. Phillips (1983) Spatial receptive fields in the cat inferior colliculus. Hear. Res. 10: 203-215.

Servière, J., W. R. Webster, and M. B. Calford (1984) Isofrequency labelling revealed by a combined $\left[{ }^{14} \mathrm{C}\right]$-2-deoxyglucose, electrophysiological, and horseradish peroxidase study of the inferior colliculus of the cat. J. Comp. Neurol. 228: 463-477.

Shaw, E. A. G. (1974) Transformation of sound pressure level from the free field to the eardrum in the horizontal plane. J. Acoust. Soc. Am. 56: 1848-1861.

Stein, B. E. (1984) Multimodal representation in the superior colliculus and optic tectum. In Comparative Neurology of the Optic Tectum, $\mathrm{H}$. Vanegas, ed., pp. 819-841, Plenum, New York.

Stillman, R. D. (1972) Responses of high-frequency inferior colliculus neurons to interaural intensity differences. Exp. Neurol. 36: 118-126.

Suga, N., and P. H.-S. Jen (1976) Disproportionate tonotopic representation for processing CF-FM sonar signals in the mustache bat auditory cortex. Science 194: 542-544.

Suga, N., and P. H.-S. Jen (1977) Further studies on the peripheral auditory system of the CF-FM bats specialized for fine frequency analysis of Doppler-shifted echoes. J. Exp. Biol. 69: 207-232.

Suga, N., and T. Manabe (1982) Neural basis of amplitude-spectrum representation in auditory cortex of the mustached bat. J. Neurophysiol. 47: 225-254.

Suga, N., J. A. Simmons, and P. H.-S. Jen (1975) Peripheral specialization for fine analysis of doppler-shifted echoes in the auditory system of the "CF-FM" bat, Pteronotus parnellii. J. Exp. Biol. 63: 161-192.

Sullivan, W. E., and M. Konishi (1984) Segregation of stimulus phase and intensity coding in the cochlear nucleus of the barn owl. J. Neurosci. 4: 1787-1799.

Takahashi, T., A. Moiseff, and M. Konishi (1984) Time and intensity cues are processed independently in the auditory system of the owl. J. Neurosci. 4: 1781-1786.

Tsuchitani, C. (1977) Functional organization of lateral cell groups of cat superior olivary complex. J. Neurophysiol. 40: 296-318.

Wenstrup, J. J., L. S. Ross, and G. D. Pollak (1983) Topographical representation of interaural intensity differences within an isofrequency lamina of the mustache bat inferior colliculus. Soc. Neurosci. Abstr. 9: 767.

Wenstrup, J. J., L. S. Ross, and G. D. Pollak (1985a) A functional organization of binaural responses in the inferior colliculus. Hear. Res. 17: 191-195.

Wenstrup, J. J., L. S. Ross, and G. D. Pollak (1985b) Segregation of binaural responses in isofrequency sheets of the mustache bat inferior colliculus. Abstract 22. Eighth midwinter meeting of the Association for Research in Otolaryngology,

Wise, L. Z., and D. R. F. Irvine (1983) Auditory response properties of neurons in deep layers of cat superior colliculus. J. Neurophysiol. 49: 674-685.

Wise, L. Z., and D. R. F. Irvine (1984) Interaural intensity difference sensitivity based on facilitatory binaural interaction in cat superior colliculus. Hear. Res. 16: 181-187.

Zook, J. M., and J. H. Casseday (1982a) Cytoarchitecture of auditory system in lower brainstem of the mustache bat, Pteronotus parnellii. J. Comp. Neurol. 207: 1-13.

Zook, J. M., and J. H. Casseday (1982b) Origin of ascending projections to inferior colliculus in the mustache bat, Pteronotus parnellii. J. Comp. Neurol. 207: 14-28.

Zook, J. M., and J. H. Casseday (1985) Projections from the cochlear nuclei in the mustache bat, Pteronotus parnellii. J. Comp. Neurol. 237: $307-324$.

Zook, J. M. J. A. Winer, G. D. Pollak, and R. D. Bodenhamer (1985) Topology of the central nucleus of the mustache bat's inferior colliculus: Correlation of single unit properties and neuronal architecture. J. Comp. Neurol. 231: 530-546. 